\title{
Effectiveness of Interactional Feedback: Implicit Learning of English Contracted Forms
}

\author{
Rajaa Aquil \\ Georgia Institute of Technology, Atlanta, USA \\ Email: rajaa.aquil@modlangs.gatech.edu
}

Received April 19 $9^{\text {th }}, 2013$; revised May $24^{\text {th }}, 2013$; accepted June $2^{\text {nd }}, 2013$

\begin{abstract}
Copyright (C) 2013 Rajaa Aquil. This is an open access article distributed under the Creative Commons Attribution License, which permits unrestricted use, distribution, and reproduction in any medium, provided the original work is properly cited.
\end{abstract}

\begin{abstract}
The role of implicit and explicit negative feedback in language acquisition has been of major concern, especially in Second Language Acquisition (SLA). Research in SLA has demonstrated that implicit negative feedback such as recast and implicit expansion are potential triggers of language development and learning. Data from two experiments, using a pretest-posttest experimental control design, of two separate groups of Arabic-speaking learners of English, one at Georgetown University (GU), and the other at American University Cairo (AUC), provides some evidence that implicit negative feedback can facilitate the acquisition and development of a complex linguistic feature, i.e., English contracted question forms. An interlanguage analysis framework, A Psycholinguistic Interlanguage Analysis Framework was devised to investigate learner's output. Interlanguage analysis findings indicate that recast can be effective in making a learner notice the contracted wh- \& yes/no questions, provided that it follows a pattern known to the learner and focuses on one point only, and that the learner is linguistically ready to learn the linguistic element.
\end{abstract}

Keywords: Recast; English Contracted Questions and Statements; Implicit Feedback

\section{Introduction}

The role of explicit and implicit instruction/learning ${ }^{1}$ as well as explicit and implicit feedback has been of major concern in Second Language Acquisition (SLA). Research in SLA demonstrated that implicit negative feedback in language learning and development, such as recast and implicit expansion, are effective in language development and learning (Adams, Nuevo, \& Egi, 2011; Akakura, 2012; Doughty \& Williams, 1998a; R. Ellis, 2005; Hulstijn, 2005; Jong, 2005; Long, Inagaki, \& Ortega, 1998; Mackey \& Sachs, 2012; VanPatten, 1996; VanPattern \& Oikkenon, 1996; Williams, 2005).

This paper reports on a small-scale empirical study investigating the effectiveness of recast, which is implicit feedback, on the perception and learning of contracted question words and utterances by Arabic-speaking learners of English. The paper is organized as follows: Section 1 gives an overview about the learning problem and pedagogical interventions employed. Section 2 discusses research on explicit and implicit learning in SLA, effective feedback as a solution to the learning problem, and the research question of the study. Section 3 reports on the experiment conducted to investigate the effectiveness of recast in the learning and development of an English structure (contracted forms of questions words and structures) by Arabicspeaking learners of English.

\section{The Learning Problem: English Contracted Form}

Arabic-speaking learners of English find contracted forms of English speech very difficult to decode and understand. They have difficulty recognizing words in the contracted form of question structures and declarative statements. For example, in a question like "What do you want to eat?" in natural running speech, not every word of the utterance is stressed and fully articulated. Instead, the question is uttered in a short and contracted form as illustrated in 1). See (Ladefoged \& Johnson, 2011 chapter 5 on connected speech).

1) Wudjyu ${ }^{2}$ wanna eat?

What do you wanna eat?

What do you want to eat?

One of the main triggers of contraction is the relationship between stressed and unstressed syllables ${ }^{3}$. When words connect or string together, unstressed syllables generally tend to be sacrificed. Vowels in these syllables are drastically reduced and consonants are blended, to the extent that L2 learners may not be able to identify the component words of an utterance.

\section{Pedagogical Interventions}

Difficulty in decoding contracted English speech is an L2

\footnotetext{
${ }^{1}$ The terms instruction and learning are used with a different focus. Instruction is used with the focus on teaching techniques, while learning is used when the focus is the learner and the developmental stages the learner goes through. ${ }^{2}$ In this example, the vowel [u] of the word you is reduced to a schwa [ə] and the consonants [d] and [y] get co-articulated, and thus a different allophone is generated, a palatalized postalveolar [j] is produced. This process occurs according to certain phrasing rules that are English-specific, such as rhythmic and prosodic rules.

${ }^{3}$ Stress is defined as an emphasis that makes a particular word or syllable stand out in an utterance. A stressed syllable is normally pronounced with more emphasis than an unstressed one.
} 
listening problem for Arabic-speaking learners of English (Aquil, 2012a, 2012b, 2012c). Much listening pedagogy concentrated on solving such learning problems in an explicit rule-based way, rather than in an implicit instruction. For example, at The American University in Cairo (AUC), I attempted various teaching techniques to solve the problem of decoding, parsing and understanding English contracted form. I made sure that students knew all the vocabulary items of the utterances they would hear. Nevertheless, this did not solve the problem because the words were studied as vocabulary words lists, in isolation and not in the co-articulated and overlapped way they are used in fluent continuous English speech. Next, I resorted to phonology and syntax, and explained to the learners the syntactic structures of the utterances and the phonological alternations that some of the syntactic constituents undergo, e.g. contraction of function words. I also taught phonological general rules of assimilation and reduction, in addition to constant exposure to the sound of the words and connected forms, but nothing changed. Finally, I turned to pronunciation drills and listening discrimination, and identification tasks were attempted ${ }^{4}$. Regardless of the type of technique and frequency and duration of exposure to any one technique, the identification of connected utterances was rarely realized.

Teaching approaches are important in foreign language instruction; the above mentioned language classroom context follows an explicit instruction approach, namely Focus on Forms. It follows a structural and piecemeal syllabus and is based on the believe that learners, after being presented and instructed with a sequence of forms and functions planned in advance and presented one by one by the teacher or the material, will eventually synthesize all the given forms and functions into a unified linguistic system (Doughty \& Williams, 1998a). In fact, as Doughty \& Williams (1998b) confirm, explicit instruction results in unproductive outcomes ${ }^{5}$.

\section{Explicit vs. Implicit Learning}

For the last two decades, SLA researchers have studied the effectiveness of explicit instruction, explicit explanation, and input processing in solving learning problems (Adams et al., 2011; Akakura, 2012; R. Ellis, 2005; Hulstijn, 2005; Jong, 2005; Long et al., 1998; VanPatten, 1996; VanPattern \& Oikkenon, 1996; Williams, 2005).

A substantial number of empirical works were carried out with adults in classrooms, as well as in laboratory settings. These studies have demonstrated the benefits of feedback, specifically interactional implicit feedback, for reviews, see (Gass \& Mackey, 2007; Long, 2007; Mackey, 2007).

Investigated studies suggest that implicit feedback does have an effect on learning and language development. For example, Long and his colleagues (1998), provide evidence from two experiments, of pretest-posttest control group design that negative feedback, e.g. recast (defined as reformulations of a learner's erroneous utterance) is noticed by learners and is used for development. Two experiments were conducted to assess the rela-

${ }^{4}$ In the discrimination task, learners were asked to discriminate between two utterances and report whether the utterances were the same or different. In the identification task, learners were trained on the sound of the utterances and in a subsequent exercise were asked to identify them.

${ }^{5}$ Doughty \& Williams (1998) states the following outcomes: 1) the form is never learned; 2) the form is learned but over generalized to wrong contexts; 3 ) the use of the form declines right after the intensive practicing ends; 4) a learned form may disappear right after a new one is introduced. tive utility of recast in L2 Japanese and Spanish. Each study showed some evidence that learners were able to learn from implicit negative feedback. Williams (2005) found that learners are able to learn form-meaning connections, even if they were not explicitly taught the connections. Also, Mackey and Sachs (2012) found that interactional implicit feedback helps in language development, even with older adult Spanish-speaking language learners.

Concerning the effectiveness of explicit vs. implicit learning, VanPatten and Oikkenon (1996) investigated whether improvement in comprehension and production was due to explicit explanation or to practice, namely, the activities used. Participants in both processing instruction and practice-only groups outperformed an explicit explanation-only group. Similarly, in recent studies, Adams et al. (2011) give evidence for a negative effect of explicit feedback, even when it is among peers and in a learner-learner interaction.

Research on child language acquisition found implicit negative feedback, such as recast, effective in language development and learning. Researchers found that parents follow their children's ungrammatical utterances with clarification requests (an implicit negative feedback), but follow grammatical utterances with parental exact repetitions and topic continuations, a form of positive evidence (Demetras, Post, \& Snow, 1986).

Bohanon \& Stanowicz (1988) quantified the occurrences of recasts and repetitions given by parents to their children's grammatical and ungrammatical utterances. They found that $70 \%$ of recasts and expansions followed children's ungrammatical utterances, and that $90 \%$ of exact repetitions followed the grammatical ones. Furthermore, Farrar (1992) found that corrective recast followed $22 \%$ of children's ungrammatical utterances, and that children produced the corrected element two or three times as often after corrective recast than after any other kind of parental feedback that could be defined as positive evidence, such as repetition and modeling.

If negative evidence, especially implicit negative evidence, as in corrective recast, has been found to be facilitative in language development in children, could the same kind of feedback be also facilitative in L2 development? This is the main question that motivated the study.

\section{Effective Feedback as a Solution to the Learning Problem}

As mentioned above, the concern over explicit vs. implicit instruction and learning motivated SLA research into which type of instructional feedback is effective in language learning and development and ought to be used in the classroom; positive or negative feedback, implicit negative or explicit feedback. Based on the findings of L1 acquisition studies in relation to negative feedback, researchers in SLA launched studies to investigate the effectiveness of negative feedback in SLA classrooms (Doughty \& Varela, 1998; Long et al., 1998; Ortega \& Long, 1997). For example Doughty \& Varela (1998) found recast, an implicit negative feedback, effective in the acquisition and development of the past tense and past conditional. As mentioned above, recast as operationalized in Ortega \& Long (1997) is feedback given by parents or caregivers in the shape of a reformulation of the children's erroneous point. In Doughty \& Varela (1998), researchers designed a natural task that necessitated the use of the past tense and past conditional for the task to be completed and the communication achieved. Their study 
compared a treatment group that received the implicit Focus on Form (FonF) technique, the corrective high-pitched reformulation of the learner's mistake (i.e., recast) with a control group that did not receive any treatment. Intonation is used here as a cue to attract the learner's attention to the mistake. The position of the recast was also very important, positioned in the discourse in such a way that the learner could notice the difference between his or her utterance and the correct one. The effect of the implicit FonF technique appeared in the students' target-like use of the two linguistic forms in question (past tense and past conditional) and also in the learner's interlanguage. The treatment group outperformed the control group in both oral and written elicitation measures and other comprehension tests. Similarly, Long and his colleagues (1998) have also reported that reactive implicit negative feedback in the form of recast is effective in achieving improvement on a previously unknown L2 structure, and is in fact more effective than positive evidence, represented as modeling and repetition.

Work on Focus on Form (FonF) opened the door to a significant body of work on feedback, investigating its effectiveness in L2 acquisition and which type is more effective (Adams et al., 2011; Akakura, 2012; Bigelow, delMas, Hansen, \& Tarone, 2006; Mackey, 1999; Mackey \& Oliver, 2002; Mackey \& Philp, 1998; Williams, 2005). For example, (Bigelow et al., 2006) found that the ability to recall recast was related to the learner's literacy level, especially if the learner's L1 orthography was different from English. Akakura (2012) examined the effectiveness of explicit instruction on L2 learners' implicit and explicit knowledge of English articles. Mackey's (1999) results pointed to a link between interactional feedback as in recast, and grammatical development.

Like the above studies, the current study's aim is to investigate which type of feedback is more effective in the development and learning of an L2 complex linguistic feature, i.e. contracted forms, by Arabic-speaking learners of English.

\section{The Research Question of This Study}

Would an isolated recast with a high pitch help learners learn the new linguistic form (contracted question form) and repair their previously uttered erroneous forms? In addition, is the learning of the contracted form reflected in the learners' interlanguage, as measured by their performance in an elicited imitation task?

\section{Experiment: Effectiveness of Recast in Learning Contracted English Question Forms}

Two experiments were conducted at AUC and Georgetown University (GU) that followed a one-shot pretest, treatment, posttest experimental/control group design. The treatment, in the experimental group, was in the form of implicit negative feedback using FonF technique. The control group just listened to a dialogue between native speakers of American English, instead of the pedagogical treatment. The whole activity in both

\footnotetext{
${ }^{6}$ Initially there were eleven; five in the control and six in the experimental. However, because one of the subjects in the control group did not give any response to the posttest, and another could not carry on the posttest in the experimental group (the experiment took place during Ramadan the Muslim fasting month) they had to be eliminated. The third subject from the experimental group had to be eliminated because the recording machine had a mechanical failure during his recording for both the tests and the treatment.

${ }^{7}$ This is the old version of TOEFL.
}

conditions (experimental and control) took around 90 minutes.

An elicited imitation task was used for pretest and posttest. The participants listened and repeated a prompt that included the contracted wh- or yes/no question. Both of the tests and the pedagogical treatment were sliced from natural occurring interactions between two native speakers of American English. See Appendixes A and $\mathbf{B}$ for a description of tests and pedagogical treatment.

\section{Method}

\section{Participants}

Participants were students studying English at the Adult Continuing Education Center at AUC; and also from a group of students studying English at the Department of English as Foreign Language (DEFL), at GU. Both groups were given consent and demographic forms to fill out. Participants were randomly assigned to either an experimental or a control group. Both groups were administered the elicited imitation task as a pretest and posttest. See Appendix A.

Eight participants came from AUC, where they were attending English classes three times a week ${ }^{6}$. Their proficiency level in English could be described as basic to beginners, since their TOEFL $^{7}$ scores ranged from 310 to 350 . Their ages ranged from 20 to 25 . Two were female and six male. They had various majors: commerce, agriculture and engineering. In their demographic forms, they indicated that they occasionally watched soap operas and sitcoms in English and that they wanted to learn English so that they could get some training before they travel for professional training in Europe or the United States.

At GU, the participants were six Arabic-speaking male students from the DEFL ${ }^{8}$. They were from Saudi Arabia, Kuwait and the United Arab Emirates. The students attended intensive English classes every day to prepare them for academic studies at American universities. Their proficiency level ranged from low intermediate to high intermediate or advanced (between 375 to 450 on the TOEFL exam ${ }^{9}$ ); and they were facing a requirement to get TOEFL scores of more than 500 in order to continue academically. Some of the students had been in the United States for one year before the study was conducted, while the others had been there for only three or four months.

\section{Materials}

1) Pretest and posttest

To test the learners' ability to produce wh- \& yes/no question, elicited imitation, a psycholinguistic technique, was used. In this technique, the subject is presented with a spoken string and asked to repeat the utterance ${ }^{10}$. It has been used to test the competence of learners in child L1 and adult L2 acquisition (BleyVroman \& Chaudron, 1994).

The items of the tests were devised in a way that ensured their simplicity, by keeping the vocabulary and syntax simple and consisting of high-frequency words, and the length of the strings was kept short in order not to overload the learners' short-term memory. Having constructed the instrument in rather

\footnotetext{
${ }^{8}$ Initially there were eight. One subject from the experimental group had to be eliminated because it was discovered after administering the tests and the treatment that he had a hearing problem. Also, a subject from the control group had to be eliminated as he stopped responding toward the end of the posttest.

${ }^{9}$ This is the old version of TOEFL.

${ }^{10}$ They were told that they had only five seconds to repeat the prompt.
} 
simple grammar and vocabulary, the researcher hypothesized that, if the learners could not repeat the utterances, the reason would be due to the difficulty to parse contracted connected English wh., yes/no questions and declarative statements.

The two alternate forms, A \& B, of the testing instruments were administered as (pre and post) in a counterbalanced-design. Each form consisted of 57 utterances produced by two male native speakers of English. See Appendix A.

2) Pedagogical treatment

The pedagogical treatment was designed according to Long's (1998) Task Based Language Teaching. To ensure that the participants had an interaction that necessitated their listening to questions, a task was devised to emulate real life reporting. In this task, the participants in the experimental group were instructed to take the role of reporters and ask an American native speaker of English questions to find out the name of a celebrity. They were told that the American native speaker of English did not have enough exposure to foreign-accented English, and would not answer any questions unless the questions were put in the kind of English he was accustomed to. The participants heard the questions through their headphones and were instructed to ask them by repeating them. Upon hearing the participants' elicitations, the researcher provided feedback, whenever necessary. That is, if the participant could not repeat the question the first time, the researcher would provide the isolated highpitched recast of the contracted wh- or yes/no question. If the participant repeated it correctly, they would hear the answer through their headphones ${ }^{11}$. Please note the examples in Appendix $\mathbf{C}$. To ensure that the participants hear natural contracted questions produced by native speakers of American English, a game along the idea of "Jeopardy!" is used (Appendix A2 and B). Two male native speakers from GU volunteered to play it. The recorded material was digitized and the contracted questions and utterances were sliced out of the recording and were used in the experimental group. As the participants heard them through their headphones they were asked to repeat them while the researcher gave implicit feedback "recast" every time the participant uttered the form erroneously.

\section{Procedure}

\section{Data Collection}

The collected data at AUC and GU was digitized and tran- scribed phonetically by the researcher. In order to control for L1 bias (since the researcher is a native speaker of Arabic) and also to verify the produced phonetic transcription, two native speakers of American English were asked to transcribe the same data. A kappa index agreement (Cohen, 1960) was calculated.

\section{Coding}

Contractions of wh- \& yes/no questions and declarative statements were analyzed in test prompts and were coded according to chunking, based on metrical analysis of the utterances, i.e. distribution of stressed and unstressed syllables resulting in contracted utterances. Chunking was operationalized as the presence of pauses after a phrase. Each phrase was coded for the following items: 1) the auxiliary verb; 2) wh-word; 3 ) the pronoun; and 4) the main verb.

\section{Scoring}

Each contracted utterance and wh- \& yes/no question in the test prompts received a score, dependent on the constituents of the contracted segment. For example, a constituent in the contracted segment was given a score of 1 ; thus, a segment that contained 4 elements, (e.g. wh-, aux. verb, pronoun, and main verb) received a score of 4 . Participants received a score based on the number of the items produced per utterance. In addition, a score for L2 target-use was also included. Every time the participant produced a correct L2 target-like use, he was given a score of 1 . Nevertheless, since learning could not take place instantaneously, as it has been quite established, (Doughty \& Williams, 1998a; Lightbown, 1998) interlanguage analysis of the acquisition development was undertaken. The aim of this analysis was to look into whether there was any change in the participants' interlanguage between the treatment and control group. See Table 1 below.

\section{Inter Transcriber and Inter Rater Agreement}

After the researcher transcribed the participants' utterances phonetically, two independent native speakers of American English were asked to transcribe the utterances and validate the researcher's phonetic transcription. One of the transcribers was familiar with phonetic transcription; however, the other was not. This affected the agreement index between them. The transcriber who was not familiar with phonetic transcription had the ten-

Table 1.

The psycholinguistic interlanguage analysis framework.

\begin{tabular}{|c|c|c|c|}
\hline & Stages & Strategies & Input/knowledge driven \\
\hline 1 & Phonological priming by L1 lexical items & $\begin{array}{l}\text { Modeling L1: } \\
\text { Priming of an L1 cognate word or similar in pronunciation }\end{array}$ & Input driven \\
\hline 2 & Phonological priming by Auditory input. & $\begin{array}{l}\text { Modeling Input: } \\
\text { Priming of a sound heard in a recognized word. }\end{array}$ & Input driven \\
\hline 3 & Phonological priming by L2 lexical items & $\begin{array}{l}\text { Modeling \& simplification by deletion or changes in } \\
\text { segments, syllables, and words }\end{array}$ & Input \& Knowledge driven \\
\hline 4 & Extrasystemic utterances & Modeling \& Trickling & Input \& Knowledge driven \\
\hline 5 & Use of intonation but lacks function words & Simplification by deletion and or changes in function words & Knowledge driven \\
\hline 6 & Canonical word order with rising intonation & $\begin{array}{l}\text { Flooding } \\
\text { Over-generalization }\end{array}$ & Knowledge driven \\
\hline 7 & Canonical word order with Question word placement & Analysis & Knowledge driven \\
\hline 8 & Subject Verb Inversion & System Learning & Knowledge driven \\
\hline 9 & Correct but not target use & Analysis \& System Learning & Knowledge driven \\
\hline 10 & Correct target-like use & Syntactic, semantic, lexical and phonological interaction & Knowledge driven \\
\hline
\end{tabular}

${ }^{11}$ The researcher manipulated when the participants could hear the previously recorded answer. 
dency to make sense of every utterance said by the participants, whether or not the utterances were meaningful. Apparently, her lack of experience and the guttural sounds of Arabic caused some problems, especially in the Cairo study.

A Kappa (Cohen, 1960) agreement of index was calculated between the two transcribers, a fair agreement of .459 was found for Cairo experimental group, and a poor agreement of .356 for Cairo control group. As for GU data, a fair agreement was found for the experimental and control groups, a 419 for the experimental and 420 for the control.

Acceptability of the participants' utterances was also investigated. Two native speakers were asked to rate the participants' utterances. Acceptability was operationalized as the condition when a native speaker rater would understand and be able to respond or answer an utterance produced by the participants. In other words, raters had the question "Is the utterance intelligible enough in your terms to answer it?" If the raters felt that it was intelligible, they gave it a point; if not, a zero was given.

A rather weak kappa agreement was achieved for both the experimental and control groups in Cairo, an agreement of .289 for the experimental pretest, and .348 for the posttest. As for the control group, an agreement of .363 was found for the control pretest, and .296 for the posttest. GU data showed a fair agreement of .433 for the experimental pretest, and .473 for the experimental posttest, while the control pretest got a poor agreement of .306 , and .347 for the control posttest.

\section{Results}

Two independent $t$ tests as a statistical procedure were conducted to investigate any gains that occurred in the number of units produced per contracted segments, and the gain in target use of the utterances. No significant difference was found between the experimental and control group in relation to the above measures in either study.

Despite the lack of statistical significance of the results, a slight change was witnessed in the experimental groups, as illustrated by the following figures. In Figure 1 (Cairo data) the experimental group started lower in both measures; however, improved in the posttests.

As for Figure 2 (GU data) the experimental group did better than the control group in both measures. The observed changes indicated that an interlanguage analysis was necessary to investigate whether some development occurred in the acquisition of the English contracted forms in the experimental groups.

\section{Data Analysis}

\section{Interlanguage Analysis}

An interlanguage analysis was carried out based on a framework in which I adapted processes involved in listening, for example, top-down (knowledge-driven) and bottom-up (inputdriven) processes. I also incorporated elements from interlanguage frameworks found in the literature (Doughty, 1998; Hammarberg, 1993; Pienemann, 1989; Tarone, 1987).

Cognitive psychologists contend that listening is a complex process (Anderson, 1976, 1983a, 1995) that involves interrelated stages and strategies. These include bottom-up or inputdriven processes, such as speech perception (identification of phonetic sounds), word recognition (deciding which word has been said), parsing (the assignment of structure to the words recognized) and interpretation (assignment of meaning). The

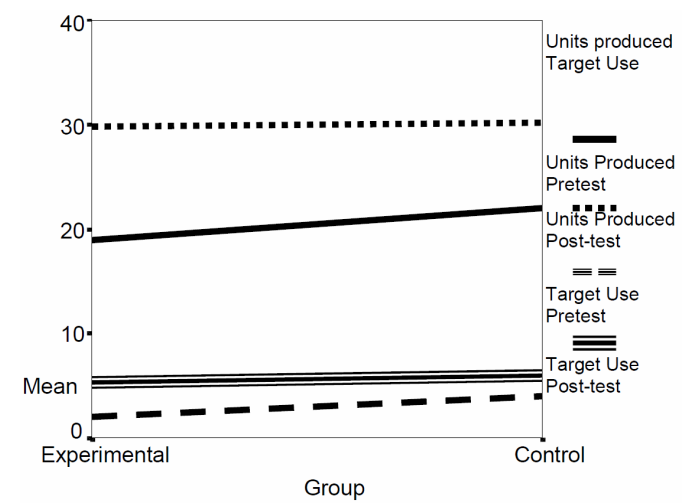

Figure 1.

Units produced \& Target Use of Cairo Experimental and Control Groups Pretest \& Posttest.

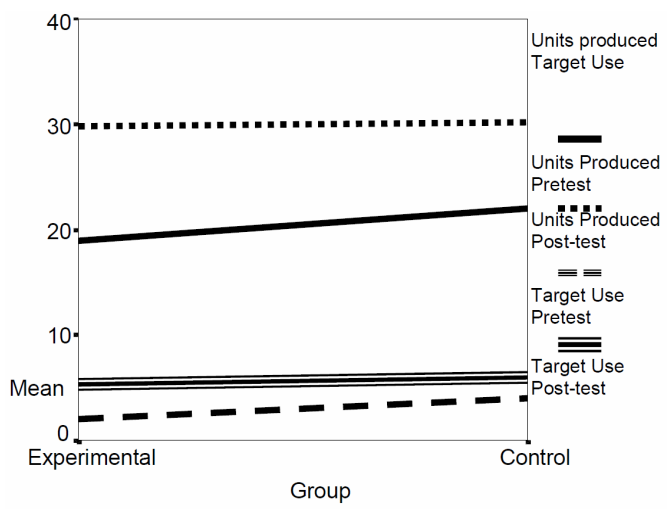

Figure 2.

Units produced and Target use of GU Experimental and Control Groups Pretest and Posttest.

top-down or knowledge-driven processes include strategies such as inferencing, predicting and checking expectations on the basis of the incoming linguistic input, knowledge and experience.

To ensure that the framework is inclusive of listening processes as well as stages and strategies of language acquisition, I constructed (A Psycholinguistic Interlanguage Analysis Framework) which is based on listening processes mentioned above and on the following frameworks: Hammarberg's (1993) learning strategies, Tarone's (1987) phonological acquisition stages, Pienemann's (1989) developmental stages, and Doughty's (1998) acquisition stages of wh-. questions (see Doughty, 1998: p. 133).

In the current analysis, learners' utterances were coded according to the following two categories: input-driven, and knowledge-driven. The input-driven category included the following strategies and stages: 1) phonological priming by L1 lexical items; 2) phonological priming by auditory input; 3) phonological priming by L2 lexical items; 4) extrasystemic formulaic utterances; and 5) using intonation, no function words. The knowledge-driven category included the following stages: 6) canonical word order with rising intonation; 7) canonical word order with placement of question words; 8) subject verb inversion; 9) correct but not target-like use; and 10) correct targetlike use. Table 1 demonstrates the stages, strategies and their sources, whether input-driven or knowledge-driven. 


\section{Input-Driven}

When learners do not have sufficient prosodic, phonological and grammatical knowledge of L2, they resort to input-driven processes, such as segment or phoneme identification, or word recognition. In this study, because Cairo learners did not have sufficient prosodic, phonological and grammatical knowledge in English, it was predicted that they would refer to inputdriven processes and their developmental stages would be geared more toward the input. The analysis conducted supported this prediction, as it was found that the subjects designated their processing strategies toward the given input. See Table 2 for processes employed by Cairo learners.

In the examples below, the learner in (1a \& b) most likely perceived the [h, $\mathrm{n}$, and o] sounds in the utterance; however he probably could not place them in the words correctly. The [o] sound in the word "office", which apparently he knew, affected his production of the contracted segment, the underlined constituent in the brackets, [Iziniz ofis]. Likewise, in data (1b) the learner perceived the nasal sound in the word "can", but because it was contracted she most likely could not parse it. However, the nasal sound in "can" primed her to produce those nonsensical words "nim, im," which also happen to be nonexistent in Arabic. In data (2c), I assume that the learner referred to his knowledge of English words and parsed the contracted segment as a word related to the English word "heart". Whereas in data (2d), I am positing that the underlined word that was pro- duced by the learner was primed by a lexical Arabic effect, since this word exists in Arabic and it means "I have".

The phonological priming and Arabic lexical effects priming decreased in occurrence in the experimental posttest performance more than they did in the control group. The average percentage of phonological priming in the experimental pretest is $74 \%$, but decreased to $19 \%$ in the posttest. As for the control group the average percentage of phonological priming was $54 \%$ in the pretest, and decreased to $26 \%$ in the posttest.

In terms of acquisition, Tarone (1987) mentions that learners pass through certain stages. Learners employ these stages to cope with the unfamiliar heard input. The tactics Tarone mentioned were found to be more among Cairo's learners. A comparison in the tactics used by learners in each study revealed the presence of these tactics $62 \%$ of the times in the experimental and control groups in the Cairo study, but nothing was found in regard to these tactics in GU data.

For example, in the data in Table 2 of GU data, the learners deleted the unstressed word in the contracted segment. In example (3e) the learner deleted the string that may have sounded as uncommon and substituted it with an open syllable cv "we" followed by the word "won". As for data in (3f) the learner deleted the whole contracted form of "wanna".

Concerning the extra-systemic structures, these are formulaic chunks and utterances that learners produce correctly and learn as "set phrases" (Doughty, 1998; Doughty \& Williams, 1998a;

Table 2.

Input-driven processes and stages as observed in Cairo data.

$$
\text { Input driven }
$$

Learners resort to input-driven strategies, and language developmental stages are shaped and driven by given input.

$$
\text { Phonological priming }
$$

The condition when a certain phonological sound affects the perception of another sound in the utterance, either through a short or long-distance effect. Learne perceives and utters a word based on the sound in a subsequent word.

\begin{tabular}{lll}
\hline & Original input & \multicolumn{1}{c}{ Student's output } \\
\hline 1. & & a. [?z.hojnin Pofis $]^{12}$ \\
Is he in his office & [nem. ju. im bai. siks] \\
Can you be ready by six? & b. \\
& ?iz. hi, kant. mo.ni] \\
Has he paid back the money? &
\end{tabular}

The condition when some words in the utterance primed the production of other words by the learner despite their absence in the original utterance. Lexical effects may sometimes be primed by L1 or L2.

2.

How do you come to know that?

[her.ti kom] [tu zat $]^{13}$

\begin{tabular}{|c|c|}
\hline \multicolumn{2}{|c|}{ Simplification through deletion } \\
\hline 3. & e. \\
\hline What do you wanna eat? & $\begin{array}{l}\text { [wi. won. i:r] } \\
\text { f. }\end{array}$ \\
\hline \multicolumn{2}{|c|}{ Extra-systemic structures } \\
\hline 4. & g. \\
\hline item (5) Test format B & Do you like horror movies? \\
\hline item (33) Test format B & Do you know? \\
\hline item (18) Test format B & Do you think? \\
\hline item (37) Test format B & But you know \\
\hline item (22) Test Format A & Where is it? \\
\hline
\end{tabular}

[San.di. ju. Kom] [tu. kom.in. ne $]^{14}$

\footnotetext{
${ }^{12}$ Data from learner (1) in the control group posttest.

${ }^{13}$ Data from learner (3) in the experimental group pretest.

${ }^{14}$ Since rising intonation even when the verb is absent denotes a question, raters accepted it despite the lack of a verb, as mentioned raters were neither phoneticians nor English grammar teachers.
} 
Huebner, 1983), before they carry on any systematic analysis of the input. These extra-systemic elements may serve as precursors, and sometimes as triggers, for further learning, as the learners' system may adjust to them some time after they appear. Intonation plays a very important role in extra-systemic structures as it renders the structure malleable and easy to remember. These structures started to emerge in the posttests of the experimental and control groups, Cairo data, $75 \%$ in the experimental and $50 \%$ in the control. This could be taken as an indication that some learning has taken place. It was amazing to find the learners able to produce contracted segments, especially since in their pretests their production was very simplified phonologically and full of nonsensical words or primed by L1 lexical terms.

\section{Knowledge-Driven}

Learners resort and use all the information they have about a given language, whether phonology, vocabulary or syntax. They also use all the strategies they have acquired interactively. The following table demonstrates the examples, illustrating the stages the learners of the experiment have gone through and the strategies they employed.

Note that at the "intonation and canonical word order" stage learners use the canonical word order of a question with a rising intonation but without supplying the auxiliary verb as in the examples of (6a-h) in Table 3 below. In fact, such utterances exist a lot in the Cairo experimental group learners' posttests and in GU's control and experimental pretests. As noticed in the examples, in the yes/no question, the auxiliary verb is missing. Interestingly, when the raters checked the acceptability of such utterances, they agreed that they were acceptable. Most likely, raters accepted the learner's output because it followed a question intonation despite the absence of the auxiliary verbs ${ }^{15}$. Extracts (6a and b) are from learners' 1 and 4 Cairo experimental posttest data, while extracts (6c-e) in Table 3 are from the GU experiment pretest, and extracts (6f-h) are from learners' 2 and 4 GU control post-test.

Learners at this stage could analyze the components of a contracted question and produce even the segments that were not salient. For example, a structure like "Does it have cheese on it?" "was produced as 'Does have cheese?" by the learners in the posttest of the experimental group in Cairo. For Cairo learners this is a major breakthrough, because their initial production of such structures in the pretest was basically unintelligible and far from being English-like.

Likewise, in the GU pre-test data, learners deleted the pronoun from the question structures. For example the structured "is it gonna rain today?" and "what's it about?" were produced by learners in the pretest as "Is gonna rain today?" and "What is about?" However, in the posttests, such cases were not as frequent. For example, learners at GU in the experimental group produced $75 \%$ of utterances that had syntactic simplification, like deletion of function word (e.g., an auxiliary, or a pronoun), whereas in their posttest they did not have one case of syntactic deletion. On the other hand, the control group had $83 \%$ of syntactic deletion instances in the pretest, and decreased to only $44 \%$ in the posttest. This could be taken as strong support for the syntactic accuracy the treatment technique has helped the participants learn.

At the System Learning stage, learners analyzed the components of the utterance and applied the knowledge they had. This was observed specifically in the data of GU. Here, learners used the knowledge they have acquired about English grammar, phonology, syntax and vocabulary to help them parse the heard input. This is exemplified by the words they substituted when they could not parse the original ones. For example in (7c) the learner substituted the word "around" by "be right here". The word used is neither different from the original in syntactic category nor in semantics. In addition, his knowledge of the phonological system might have helped him replace the unparsed word "around" with a word that had a similar sound [r] as in "right here". The same argument applies to (7b). The learner substituted with words that fit syntactically and semantically. The learner most likely could not hear the contracted segment in "Is there good food there?" and substituted it with "did they get food in there?" His knowledge of English might have helped him to produce appropriate syntactic and semantic words.

Table 3.

Knowledge-driven strategies.

Knowledge-driven

Learners use knowledge they have about L2 grammar, phonology, syntax and vocabulary to parse heard input.

Intonation and canonical word order

Learners use the canonical word order of a sentence, but with a rising question intonation.

\begin{tabular}{|c|c|}
\hline Original input & Learner output \\
\hline $\begin{array}{l}\text {. Do you have your textbook? } \\
\text { a. D. Did you ask him about the accident? } \\
\text { c. Do you have your ID? } \\
\text { d. Do you know where it is? } \\
\text { e. Is he absent? } \\
\text { f. Do you know if there's a good movie in town? } \\
\text { g. Do you have your textbook? } \\
\text { h. Do you have your textbook? }\end{array}$ & $\begin{array}{l}\text { 6. } \\
\text { a. You have your textbook? } \\
\text { b. You ask about accident? } \\
\text { c. You have your ID? } \\
\text { d. You know where it is? } \\
\text { e. He's absent? } \\
\text { f. You know if there's a good movie in town? } \\
\text { g. You have your textbook? } \\
\text { h. You have textbook? }\end{array}$ \\
\hline Analysis and provision of previously missing functional words & learning \\
\hline $\begin{array}{l}7 . \\
\text { a. Are you gonna be around this afternoon? } \\
\text { b. Is there good food there? }\end{array}$ & $\begin{array}{l}\text { c. Are we going to be right here this afternoon? } \\
\text { d. Did they get food in there? }\end{array}$ \\
\hline
\end{tabular}

\footnotetext{
${ }^{15}$ Since rising intonation even when the verb is absent denotes a question, raters accepted it despite the lack of a verb, as mentioned raters were neither phoneticians nor English grammar teachers.
} 
Of utmost interest and importance are the findings related to the learners' interlanguage and to their perception and acquisition of contracted statements and wh- and yes/no contracted questions, phonologically and grammatically. However, there are differences in the strategies used by the learners. GU learners used strategies that referred to their knowledge of English vocabulary and grammar in parsing the auditory input. Actually, the advanced learners used both input and knowledge-based inferential strategies. The learners in Cairo, on the other hand, because of their lack of sufficient knowledge of English grammar and vocabulary, employed input-driven strategies, some based on L1, and some on the auditory input. They employed knowledge-driven strategies only when the structure or components were familiar.

This finding supports the notion that the manipulation of input in the form of focus on form could be effective, since the learners' default attention was on the input. In fact, although the results do not show that there is a statistically significant difference in target-like use ${ }^{16}$, and in the number of units produced between the experimental and control groups, the interlanguage analysis conducted reveals that the experimental group, especially in the Cairo study, started noticing the form. After the treatment, contracted forms started to emerge. It is true that they appeared as extra-systemic elements; nevertheless, they are there; perhaps as precursors for learning, that could trigger further learning, especially when the learner starts to analyze the input (Vihman, Velleman, \& McCune, 1994).

A gratifying result is the progress the experimental group in GU has made in terms of avoiding syntactic simplifications and deletions, as demonstrated in Table 4. A rather strong support for the treatment is that the control group did not do as well as the experimental in this regard. Table 4 demonstrates that GU learners in the control group produced correct but not targetlike items $33 \%$ of the time. The learners in the experimental group did not produce any non-target items, but actually produced correct and target-like items $88 \%$ of the time in the posttest.

Solution of the learning problem, contracted questions and statements, did not take place at the expense of communication and meaning. On the contrary, meaning and communication were vital and crucial elements in making the technique succeed. The study was designed to make sure that the participants were exposed to natural running speech, and were given a pedagogical treatment, which ensured the emulation of real-life tasks as in reporting. Hence, there was no dichotomy between natural language as spoken among native speakers of English and classroom-comprehensible input.

The findings reveal that, because the investigated form contracted wh- \& yes/no, and contracted statement involve multiple linguistic components, for example, phonology, prosody, syntax, and semantics, some prior knowledge is probably necessary in order to make the best use of the corrective potential power of recast (Saxton, 1997).

This brings us to the question of whether there is a relationship between implicit and explicit instruction/learning, and whether prior knowledge is explicit or implicit. In other words, should learning follow Anderson's theory of skill acquisition (Anderson, 1982, 1983b; DeKeyser, 1998, 2001; VanPatten, 2010)?

DeKeyser (1998) says that SLA should follow the theory of

\footnotetext{
${ }^{16}$ This could be attributed to the small number of the participants.
}

skill acquisition by introducing linguistic information or knowledge in the form of declarative knowledge, and via practice it becomes procedural and then automatic; in other words, explicit learning becomes implicit. I would like to argue along the lines of DeKeyser's (1998) and VanPatten's (2010) argument that both explicit and implicit knowledge and learning are in place, and we cannot separate between them. VanPatten regards mental representation as abstract and implicit knowledge that underlies all language, while skill refers to the use of language. I add that skill can be developed and enhanced through practice, especially if it is carried out implicitly in communicative classroom activities, with the incorporation of implicit negative feedback, such as recast, whenever it is necessary.

The findings of this study point to the possible interaction between explicit and implicit learning, specifically the weak interface position (R. Ellis, 2005: p. 144). According to Ellis (2005) researchers have three positions in relation to the interface between explicit and implicit learning. The first version posits that explicit learning can turn into implicit knowledge through practice only when the learner is developmentally ready to acquire the linguistic element (Check Processability Theory (PT) Pienemann, 1989, 2007).

The second version holds that explicit knowledge contributes indirectly to the acquisition of knowledge implicitly by involving and promoting some of the top-down or knowledge-driven information like declarative rules (N. Ellis, 1994). The third version posits that learners use their explicit knowledge to produce output that in turn is used as input for implicit learning to take place (Schmidt \& Frota, 1986; Sharwood Smith, 1981).

The findings of the interlanguage analysis in the current study give support that the three versions of interface are present. For example, we can witness the presence of the weak version as it is observed when learners in both studies do not produce the contracted form correctly until they go through certain input-driven and knowledge-driven stages and strategies. The evidence for the presence of the second version can be found in the data of GU learners, especially if compared with the Cairo data. As mentioned, the GU learners were linguistically more proficient than Cairo learners, and thus were able to tap into the declarative knowledge of rules in parsing the heard input. As for the third version, since it is related to output and production, I argue that it reflects practice. There is no better indication of its presence than the increase in the number of produced units and their L2 target-like use, as seen in the data of Cairo learners.

\section{Conclusion}

The present paper sheds some light on two major research concerns in SLA, i.e. linguistic knowledge and development of a given linguistic feature. Data from two experiments conducted on two separate groups of Arabic-speaking learner of English, at the American University Cairo (AUC) and Georgetown University (GU) gives some evidence that implicit negative feedback, as in "recast," could be effective in the learning and the development of a complex English language structure, namely the contracted forms in questions and declarative statements. The pedagogical treatment based on Fonf, and the implicit feedback, as in "recast," provided by the researcher when necessary helped in the learning and development of contracted forms. This was observed in the learner's interlanguage data, especially the emergence and increase of contracted forms in 
the learners' output, even though these were extrasystemic formulaic-like utterances. A framework, A Psycholinguistic Interlanguage Analysis Framework, was devised to investigate the data. The framework was based on cognitive listening processes, input and knowledge-driven, as well as different interlanguage frameworks established in the literature.

Interface between explicit and implicit learning was also demonstrated in the findings of the analysis, specifically with GU learners. These learners did better than their peers in Cairo because they were able to tap into their explicit/implicit knowledge that they learned at GU, and also because they were able to utilize both input as well as knowledge-driven strategies while processing the input.

\section{REFERENCES}

Adams, R., Nuevo, A. M., \& Egi, T. (2011). Explicit and implicit feedback, modified output, and SLA: does explicit and implicit feedback promote learning and learner-learner interactions? The Modern Language Journal, 11, 42-63. doi:10.1111/j.1540-4781.2011.01242.x

Akakura, M. (2012). Evaluating the effectiveness of explicit instruction on implicit and explicit L2 knowledge. The Language Teaching Research, 16, 9-37. doi:10.1177/1362168811423339

Anderson, J. (1976). Language, memory, and thought. Hillsdale, New York: Erlbaum.

Anderson, J. (1982). Acquisition of cognitive skill. Psychological Review, 89, 369-406.

Anderson, J. (1983a). The architecture of cognition. Cambridge, MA: Harvard University Press.

Anderson, J. (1983b). Four operating principles and input distribution as explanation for underdeveloped and mature morphological systems. In K. Hyltenstam \& A. Viberg (Eds.), rogression and regression in language (pp. 309-339). Cambridge: Cambridge University Press.

Anderson, J. (1995). Learning and memory. New York: John Wiley \& Sons.

Aquil, R. (2012a). L1 shapes L2 auditory representation: Elicited imitation of Arabic speaking learners of English International Journal of Applied Linguistics \& English Literature (IJALEL), 1, 39-63.

Aquil, R. (2012b). Listening to English connected speech: A problem and solutions Arab World English Journal, 3, 329-364.

doi:10.1037/0033-295X.89.4.369

Aquil, R. (2012c). Phonology and applied linguistics meet in teaching listening. Arab World English Journal, 3, 168-189.

Bigelow, M., delMas, B., Hansen, K., \& Tarone, E. (2006). Literacy and the processing of oral recasts in SLA. TESOL Quarterly, 40, 125. doi: $10.2307 / 40264303$

Bohannon, M., \& Stanowicz, L. (1988). The issue of negative evidence: Adult responses to children's language errors. Developmental Psychology, 24, 684-689. doi:10.1037/0012-1649.24.5.684

DeKeyser, R. (1998). Beyond focus on form: Cognitive perspectives on learning and practicing second language grammar. In C. Doughty \& J. Williams (Eds.), Focus on Form in Classroom Second Language Acquisition. Cambridge: Cambridge University Press.

DeKeyser, R. (2001). Automaticity and automatization. In P. Robinson (Ed.), Cognition and second language acquisition. New York: Cambridge University Press. doi:10.1017/CBO9781139524780.007

Demetras, M. J., Post, K. N., \& Snow, C. E. (1986). Feedback to first language learners: The role of repetitions and clarification questions. Journal of Child Language, 13, 275-292.

doi:10.1017/S0305000900008059

Doughty, C. (1998). Acquiring competence in a second language: Form and function. In H. Byrnes (Ed.), Learning foreign and second languages: Perspective in research and scholarship (pp. 128-156). New York: The Modern Language association of America.

Doughty, C., \& Varela, E. (1998). Communicative focus on form. In C. Doughty \& J. Williams (Eds.), Focus on form in classroom second language acquisition. Cambridge: Cambridge University Press.
Doughty, C., \& Williams, J. (1998a). Focus on form in classroom second language acquisition: Cambridge University Press.

Doughty, C., \& Williams, J. (1998b). Pedagogical choices in focus on form. In C. Doughty \& J. Williams (Eds.), Focus on Form in Classroom Second Language Acquisition. Cambridge: Cambridge University Press.

Ellis, N. (1994). Introduction: Implicit and explicit language learning: an overview. In N. Ellis (Ed.), Implicit and explicit learning of languages. San Diego, CA: Academic Press

Ellis, R. (2005). Measuring implicit and explicit knowledge of second language: A psychometric study. Studies in Second Language Acquisition (SSLA), 27, 141-172.

Farrar, M. J. (1992). Negative evidence and grammatical morpheme acquisition. Developmental Psychology, 28, 90-98. doi:10.1037/0012-1649.28.1.90

Gass, S. M., \& Mackey, A. (2007). Input, interaction and output in second language acquisition. In B. Vanpatten \& J. Willaims (Eds.), Theories in second language acquisition: An introduction (pp. 175199). Mahwah, NJ: Erlbaum.

Hammarberg, B. (1993). The course of development in second language phonology acquisition: A natural path or strategic choice In K. Hyltensatan \& A. Viberg (Eds.), Progression \& regression in language: sociocultural, neuropsychological, and linguistic perspectives (pp. 439-463). Cambridge: Cambridge University Press.

Huebner, T. (1983). Linguistic systems and linguistic change in an interlanguage. Studies in Second Language Acquisition (SSLA), 6, 3353. doi: $10.1017 / \mathrm{S} 0272263100000280$

Hulstijn, J. H. (2005). Theoretical and empirical issues in the study of implicit and explicit second-language learning. Studies in Second Language Acquisition (SSLA), 27, 124-140. doi:10.1017/S0272263105050084

Jong, N. (2005). Can second language grammar be learned through listening? An experimental study. Studies in Second Language Acquisition (SSLA), 27, 205-234.

Ladefoged, P., \& Johnson, K. (2011). A course in phonetics (6th ed.). Boston, MA: Wadsworth.

Lightbown, P. (1998). The importance of timing in focus on form. In C. Doughty \& J. Williams (Eds.), Focus on Form in Classroom Second Language Acquisition (pp. 177-196). Cambridge University Press.

Long, M. (1998). Focus on form and task based language teaching. University of Hawaii Working Papers, 16, 35-49.

Long, M. (2007). Problems in SLA. Mahwah, NJ: Erlbaum.

Long, M., Inagaki, S., \& Ortega, L. (1998). The role of implicit negative feed-back in SLA: Models and recasts in Japanese and Spanish. The Modern Language Journal, 82, 357-370. doi:10.1111/j.1540-4781.1998.tb01213.x

Mackey, A. (1999). Input, interaction, and second language development: Empirical study of question formation in ESL. Studies in Second Language Acquisition (SSLA), 21, 557-587. doi:10.1017/S0272263199004027

Mackey, A. (2007). Conversational interaction in second language acquisition: A collection of empirical studies. Oxford: Oxford University Press.

Mackey, A., \& Oliver, R. (2002). Interactional feedback and children's L2 development. System, 30, 459-477. doi: 10.1016/S0346-251X(02)00049-0

Mackey, A., \& Philp, J. (1998). Conversational interaction and second language development: Recasts, responses, and red herrings? Modern Language Journal, 82, 338-356. doi:10.1111/j.1540-4781.1998.tb01211.x

Mackey, A., \& Sachs, R. (2012). Older learners in SLA research: A first look at working memory, feedback, and L2 development. Language Learning, 62, 704-740. doi:10.1111/j.1467-9922.2011.00649.x

Ortega, L., \& Long, M. (1997). The effects of models and recasts on the acquisition of object topicalization and adverb placement in L2 Spanish. Spanish Applied Linguistics, 65, 65-86.

Pienemann, M. (1989). Is language teachable? Psycholinguistic experiments and hypotheses. Applied Linguistics, 10, 52-79. doi:10.1093/applin/10.1.52

Pienemann, M. (2007). Processability theory. In B. VanPatten \& J. Wil- 


\section{R. AQUIL}

liams (Eds.), Theories in second language acquisition: An introduction (pp. 137-154). Mahwah, NJ: Erlbaum.

Saxton, M. (1997). The contrast theory of negative input. Journal of Child Language, 24, 139-161. doi:10.1017/S030500099600298X

Schmidt, R., \& Frota, S. (1986). Developing basic conversational ability in a second language: A case study of an adult learner. In R. Day (Ed.), Talking to learn: Conversation in second language acquisition (pp. 237-369). Rowley, MA: Newbury House.

Sharwood Smith, M. (1981). Consciousness-raising and the second language learner. Applied Linguistics, 2, 159-169.

doi:10.1093/applin/2.2.159

Tarone, E. E. (1987). Some influences on the syllable structure of interlanguage phonology. In G. Ioup \& S. Weinberger (Eds.), Interlanguage phonology: The acquisition of a second language sound system (pp. 70-85). Cambridge: Newbury House Publishers.
VanPatten, B. (1996). Input processing and grammar instruction: Theory and research. Norwood, NJ: Ablex Publishing Corporation.

VanPatten, B. (2010). The Two Faces of SLA: Mental representation and skill. International Journal of English Studies, 10, 1-18.

VanPattern, B., \& Oikkenon, S. (1996). Explanation versus structured input in processing instruction. Studies in Second Language Acquisition, 18, 495-510. doi:10.1017/S0272263100015394

Vihman, M., Velleman, S., \& McCune, L. (1994). How abstract is child phonology? Toward an integration of linguistic and psychological approaches. In M. Yavas (Ed.), First and second Language Phonology (pp. 439-469). Sand Diego: Singular Publishing Group.

Williams, N. J. (2005). Learning without awareness. Studies in Second Language Acquisition (SSLA), 27, 269-304.

doi: $10.1017 / \mathrm{S} 0272263105050138$ 


\section{Appendix A}

\section{Pretest/Posttest Instrument Pretest/Post-Test Form A}

Eating Out

1. Are we going out to eat tonight?

2. Is there good food there?

3. Can you be ready by six?

4. What do you wanna eat?

5. Does it have cheese on it?

6. But I thought you didn't like cheese.

7. Well, Italian cheese is different.

8. Then that will take us to Paolos.

9. I wanna go with you.

10. Please take the basket from here.

11. Could have gone if they'd asked us.

12. I'd like to return this soup it has a fly in it.

13. She had her dinner with him.

\section{The weather}

14. Is it gonna rain today?

15. Did you hear anything on the radio about the weather?

16. Is it cold in your country?

17. Did it snow there?

18. Does it snow a lot there?

19. It doesn't snow much?

20. I don't like rain.

At a bank

21. Where is the withdrawal slip?

22. Where is it?

23. Do you know where it is?

24. When will he be in his office?

25. He is always on time.

26. She is in her office by 10 o'clock.

27. Then you should come back at 1 o'clock.

28. Have you forgotten anything?

29. How do you come to know that?

30. He won't help me unless you ask him.

31. Has he paid back the money?

32. He has a lot of money.

33. They have lots of money.

34. I wonder how this confusion is caused.

35. Do you know the procedure of this application?

36. This matter is not yet resolved.

37. Well we could have made it if they showed us the way.

\section{At school}

38. Did you know about the pre-registration procedure?

39. She didn't tell me.

40. I'm from Belize.

41. I should have gone with you.

42. Is he absent?

43. His mother is not home yet.

44. Is she in this class?

45. She visited him.

46. She had her dinner with him.

47. He had a fight with her.

48. Were you in class yesterday?

49. Do you know what happened to them?

50. Did you ask him about the accident?

51. Did you tell him about the accident?

52. Did you ask them about the accident?

53. He didn't tell them.

54. Should we call them.
55. I don't wanna go with him.

56. Could you give me a ride.

57. I won't give you a ride unless you give me a big hug.

\section{Pretest/Post-Test Form B}

Going to the Movies

1. Are you going to the movies tonight?

2. Are you going to be around this afternoon?

3. Do you know if there are any good movies in town?

4. Repeat that one.

5. Do you like horror movies?

6. Is that movie about a haunted house?

7. Why don't you like that story?

8. What is it about?

9. Do you want to come with me?

10. I wanna go with you.

\section{The weather}

11. Is it cold and windy outside?

12. When will the storm be over?

13. Is it raining too?

14. Why me in this weather?

15. Was it this cold last night?

16. Is it freezing outside?

17. But don't realize how cold it is outside?

18. Do you think you will freeze?

19. Aren't you gonna take the dog for a walk?

20. I think you should go now.

21. What is the problem, why aren't you taking the dog out?

22. You will need the leash to take the dog out.

23. I took the dog out last night.

24. It was a great walk last night with the dog.

25. Oh, it is not so bad outside.

26. I don't like dust.

27. I don't think he's gonna make it till tomorrow.

28. The dog really needs to go for a walk outside.

29. You will be fine.

\section{At a library}

30. Can I help you?

31. Please take this baseball from here.

32. Do you have your ID?

33. Do you know where my file is?

34. Is there a fine?

35. I wonder when this confusion was made.

36. This matter needs to be resolved.

37. Did you know about the pre-registration procedure?

38. What time will professor Smith be back?

39 . Is he in his office?

40. He is in his office by 1:00.

41. Can you stop by and see him.

42. I won't give you your grade unless you get your book.

43. Do you have your textbook?

44. By next year I won't be here.

45. Were you absent yesterday?

46. I should've gone with you.

47. What is your English professor's name?

48. I'm from Tamir.

\section{Shopping}

49. Where do you generally do your shopping?

50. Do you mean clothes shopping or food shopping?

51. I generally go to Bloomingdales.

52. Where did you buy that? 
53. When did you buy them?

54. Did you get that in the shoe department?

55. Did you buy that matching Gucci bag?

56. Did that cost a lot?

57. But I thought the sale was on.

\section{A2 Game of Jeopardy}

The game took place between the researcher and two native speakers of American English. Please see below the instructions that were given to native speakers of English playing the game. The whole conversation was recorded in a recoding booth, and digitized. Subsequently, the contracted statements and questions constructions were sliced off the recording and used for the pretest and posttest. The topics were everyday topics which include survival functional language items: Eating out, the weather; At a bank, At school, Going to the movies, At the library, and Shopping. For each topic, an introduction summarizing the situation was given by the researcher to the native speakers for the purpose of establishing context, as in the following:

"The following conversation is between two friends. They have the habit of going out every Saturday night. It is Saturday night and they are discussing where to go and what to eat. The utterances you are about to hear are statements given by one friend in answer to another friend. Please provide the proper question to the given statement as quickly and naturally as possible."

The researcher uttered a sentence that was an answer to a question to be provided by the native speakers. The first to utter the question would be the winner. Here is an example:

1) Response/prompt from the researcher

"Sure, we're going out to eat tonight.

We're going to Paolo's."

Expected question: (from the native speaker)

"Are we going out to eat tonight?"

2) Response/prompt from the researcher

"But of course, there is good food there."

Expected question:

"Is there any good food there?"

3) Response/prompt from the researcher

"OK. I'll be ready by six."

Expected question:

"Will you be ready by six"?

\section{Appendix B}

\section{Pedagogical Treatment Material Development}

Guess the celebrity

Instructions to native speakers:

Your task is to carry on a conversation asking and answering questions. One of you thinks of a celebrity from the given names below but does not reveal the person to his partner. Some of the characters are fictitious and historical and you may not have enough information about. In such cases, please speculate. The partner's task is to ask questions in order to figure out who that celebrity is. If you happen to feel that you know the person, please refrain from mentioning their name until the end of the task. Please ask a variety of question forms, wh. and yes/no questions. Also make sure your questions are related to the following themes and topics. Thank you for your cooperation.

\section{The celebrities \\ Women: \\ Jacqueline Kennedy \\ Marilyn Monroe \\ Princess Diana}

Queen Elizabeth II

Madonna

Indira Gandhi

Sophia Loren

Margaret Thatcher

Cleopatra

Hillary Clinton

Themes and topics

Whether the celebrity is dead or alive and their health-related matters.

The celebrity's taste in clothes

The celebrity's taste in music

The celebrity's involvement in sports

The celebrity's favorite sports

The celebrity's accomplishments and achievements

The celebrity's lifestyle

The celebrity's bad side, if there is any

\section{Appendix C}

\section{Example of Given Feedback}

The experimental group was exposed to the instructional condition where they got:

1) Recast, with high pitch, of an isolated (contracted wh- + aux or yes/no) phrase.

2) Expansion, with a related declarative utterance.

3) Expansion with a related declarative utterance followed by recast with high pitch of (contracted wh- + aux or yes/no) phrase, in one exchange.

The following is the format all the recast prompts followed:

The phonetic and intonation representation.

Heard Prompt through the headphones

Is she alive or dead?

I $\int \mathrm{i}$ alaivor $\mathrm{d} 3 \mathrm{~d}$

Recast with high pitch of an isolated phrase:

I 1

Expansion with a related declarative utterance:

I'm alive.

Expansion with a related declarative utterance, followed by recast with high pitch of (contracted wh- + aux) phrase, in one exchange.

I'm alive. Is she alive or dead?

An example from the pedagogical treatment discourse

Prompt: Is she alive or dead?

Student: no response

Teacher: Is she?

Student: no response

Teacher: I am alive. My father is dead.

Student: ehh.m

Teacher: I am alive, my father is dead. Is she alive or dead?

Student: She live or dead? (Rising intonation)

Teacher: Is she, alive or dead

Student: Is she alive or dead?

Agent: She is dead. This person is dead. 